\title{
Mental Health Status of Patients With Mild Traumatic Brain Injury Admitted to Shahid Beheshti Hospital of Kashan, Iran
}

\author{
Esmaeil Fakharian ${ }^{1}$; Abdollah Omidi ${ }^{2}$; Elham Shafiei ${ }^{1{ }^{1}}$; Arash Nademi $^{3}$ \\ ${ }^{1}$ Trauma Research Center, Kashan University of Medical Sciences, Kashan, IR Iran \\ ${ }^{2}$ Department of Clinical Psychology, Kashan University of Medical Sciences, Kashan, IR Iran \\ ${ }^{3}$ Department of Statistics, Ilam Branch, Islamic Azad University, Ilam, IR Iran \\ ${ }^{*}$ Corresponding author: Elham Shafiei, Trauma Research Center, Kashan University of Medical Sciences, Kashan, IR Iran. Tel: +98-3655620634, Fax:+98-3655620634, \\ E-mail: e_shafiey59@yahoo.com
}

Received: January 16, 2014; Revised: November 14, 2014; Accepted: February 14, 2015

\begin{abstract}
Background: Planning for providing mental health services to the mentally patients due to brain injury need awareness of mental health status of the patient.

Objectives: This study aimed to assess the mental health of patients with mild TBI.

Patients and Methods: The descriptive cross-sectional study was performed on 286 patients with mild TBI who were admitted to department of neurosurgery of Shahid Beheshti Hospital, Kashan, Iran, during the first eight months of 2013. Enrolled patients were 15 to 70 years old who able to respond to questionnaires. The Brief Symptom Inventory (BSI) questionnaire is used to assess the mental health status of the patients. The data were presented using logistic regression and descriptive statistics.

Results: A total of 286 patients, $79.7 \%$ males and 20.3\% females with male to female ratio of 4:1, completed the study. Female had significantly higher Global Severity Index (GSI) compared to males. There was a significant association between, psychologic disorders' symptoms and age $(\mathrm{P}=0.00)$. The mean $(\mathrm{SD})$ of GSI on the Symptom Checklist-90 (SCL-90) was $1.39(0.58)$.

Conclusions: This study showed that $36 \%$ of the patients with mild TBI symptoms had mental health problems. Given the high rates of psychologic disorders among patients with mild TBI, it is necessary to reduce the factors that caused the disorder.
\end{abstract}

Keywords: Mental Health; Psychological Problems; Brain Injury

\section{Background}

Traumatic Brain Injury (TBI) is one of the most common types of traumas and the major cause of mortality among various types of traumatic events (1-3). Based on report 2003 of Center of Disease Control, the expenses for TBI was 56 billion Dollars in the United States $(4,5)$. The severity of $70 \%$ to $90 \%$ of TBIs is mild (6). In a study done in Kashan City, 429 per 100000 people had experienced TBI. This rate is more than that of some countries such as Australia, France, Canada, Spain, Sweden, and the United States. Moreover, based on the 2005 report, the cost of one night admission in hospital is on average 316654 Iranian Rials (IRR) for each patient (7). The results of another study in Kashan City showed that in 2004, more than one billion was spent on treatment of trauma patients (8). Researches showed a high rate of psychologic problems in the patients with TBI (9-11). General estimations showed that almost half of the patients after serious TBI, more than half after moderate TBI, and about $10 \%$ after mild TBI are affected by stable neuropsychologic problems (12). According to DSM-IV-TR, two major groups of TBI symptoms are cognitive dysfunction and behavioral disorders. From behavioral aspects, the major symptoms are associated with the changes of personality, depression, increased im- pulsiveness, and aggressiveness (13). In addition, there are common outcomes as anxiety and depression with TBI (14, 15). Lishman emphasized considerably on the association between TBI and formation of mental disorders (16). It is not surprising that the risk of these disorders increases after TBI as major part of brain such as forehead and parietal lobes are susceptible to injury and they are the center of mental disorders. For example, most of the studies showed that TBI can increase the risk of mental disorders (17).

It is assumed that the mental disorders and other neurobehavioral problems are increased with the severity of brain damage (18). Regarding the severity of TBI, the results of the study by Fann et al. (19) showed the prevalence $49 \%$ of mental disorders in the first year after moderate to severe TBI, $34 \%$ after mild TBI, and $18 \%$ in control group. The researchers found that both moderate to severe TBI and mild TBI increase the risk of psychologic dysfunction.

\section{Objectives}

The present study aimed to evaluate the mental health condition among patients with mild TBI. The specific goal of the study was determining the prevalence of mental and psychologic disorders and associated demographic factors. 


\section{Patients and Methods}

This descriptive cross-sectional study was conducted by the collaboration of Trauma Research Center and Development Center for Clinical Research, in TrainingHealth Hospital of Shahid Beheshti, Kashan of University Medical Sciences, Kashan, Iran, from March to November 2013.

The number of patients with mild TBI was 1300 in 2013. A total of 286 patients with mild TBI, who were 15 to 76 years old, were enrolled. The patients were excluded if they had a psychiatric or neurologic disease or were unable to collaborate with the neuropsychologist because of severe language or attention deficits. The patients with TBI were selected by sampling method after obtaining consent. Two types of questionnaires were given to the patients. The first questionnaire consisted of demographic information (age, sex, marital status, job, education level) and the second questionnaire was Brief Symptom Inventory (BSI) including 53 questions and nine subscales, which is the summary of Symptom Checklist-90-Revised (SCI90-R) questionnaire, and a Global Severity Index (GSI), which reflects the clinical severity of all symptoms (20). To calculate the GSI, the total scores obtained from the following nine symptoms were calculated and the resulting number was divided by the number of test questions (21). Its purpose was evaluation of psychologic symptoms reported by patients with psychologic problems. This questionnaire was introduced by Dragotis et al. (1973) and was based on the clinical experiences with psychometric analyses, was revised, and its final form was provided in 1976. These instruments showed acceptable validity and reliability (0.83 and 0.87 , respectively) in a study in Iran (22). Scores on each subscale of the BSI were converted to Z-scores and patients were categorized as case if the Tvalues of the GSI or of at least two BSI subscales were $\geq$ 63 (23).

The responses to each of the questionnaire items were scored in a five-point scale ranging from never to severe. In addition to three indices of total distress, positive symptom distress, and total positive symptom, some information was provided based on nine domains of distress. The questions included somatization, compulsiveobsessive behavior, sensitivity in mutual relationships, depression, anxiety, aggressiveness, phobia, and paranoid as well as psychotic thought. The applied questionnaire in the study had some extra questions about sleep and appetite disorders.

\subsection{Statistical Analysis}

Descriptive analyses were performed using SPSS 20.0 (SPSS Inc, Chicago, Illinois, the United States). Chi square test was used to compare the characteristics of patients with TBI regarding the presence of symptoms of psychologic disorders. For multivariate analysis, the logistic regression was used to assess the effect of demographic factors on psychologic disorders in the patients with TBI.
The included variables were sex, occupation level, marital status, age, and history of mental disorder. A P value < 0.05 was considered statistically significant.

\section{Results}

Among 286 TBI patients, 228 patients (79.7\%) were male and the mean (SD) of participants' age was 33.46 (13.08) years (range, 15-65 years; median, 31.50). The results of chi-square test and the data on demographic characteristics in patients with and without symptoms of psychologic disorders are shown in Table 1 . The frequency of mental disorders was significantly different between females and males $(\mathrm{P}=0.038)$. There was a significant association between, symptoms of psychologic disorders and marital status as the divorced patients had severe mental disorders compared to the married and single ones $(\mathrm{P}=0.009)$. Moreover, there was a significant association between education and mental disorder symptoms $(\mathrm{P}=0.032)$. The symptoms of psychologic disorders reduced in proportion to the increase in education level. There was no a significant association between economic status and symptoms of psychologic disorders $(\mathrm{P}=0.437)$. Among 48 people with symptoms of psychologic disorders, 33 (68.8\%) were male and 15 (31.2\%) were female. Symptoms of psychologic disorders were seen in $43.8 \%$ of patients with TBI who had and occupation.

Table 2 displays mean scores of each of the BSI dimensions obtained by women and men. Mean of scores of the GSI was significantly higher in woman than in men. The maximum mean of scores of the scales among men was dedicated to obsession and the lowest was dedicated to somatization and phobia with. The maximum mean of scales scores among women was in anxiety and the lowest was dedicated to anger/hostility scale. The results of logistic regression analysis are presented in Table 3. A logistic regression model with the following predictor variables was used: sex, occupation status, economic status, marital status, age, and history of mental disorder. The final model showed that the variables of history of mental disorder $(P<0.05)$, staff $(P<0.0001)$, and age $(P=0.03)$ were significant predictors of developing psychologic disorders.

\section{Discussion}

The results of our study showed that $36 \%$ of the patients with mild TBI had symptoms of psychologic disorders. The comparison of the results of various investigations on symptoms of psychologic disorders in other countries including the study by Fann et al. (19) showed that symptoms of psychologic disorders in this study were in line with the findings of the studies in other countries regarding patients with mild TBI. The present findings showed that the prevalence of depression in TBI ranges from $17 \%$ to $53 \%$, which is in accordance with the results of the previous studies $(24,25)$. 
Fakharian E et al.

Table 1. Demographic Characteristic of Patients With and Without Symptoms of Psychologic Disorders ${ }^{\text {a }}$

\begin{tabular}{|c|c|c|c|}
\hline \multirow[t]{2}{*}{ Demographic Variables } & \multicolumn{2}{|c|}{$\begin{array}{c}\text { Presence of Symptoms } \\
\text { of Psychologic Disor- } \\
\text { ders }\end{array}$} & \multirow[t]{2}{*}{ PValue } \\
\hline & $\operatorname{No}(\mathrm{N}=238)$ & Yes $(N=48)$ & \\
\hline Sex & & & 0.038 \\
\hline Male & $195(81.9)$ & $33(68.8)$ & \\
\hline Female & $43(18.1)$ & $15(31.2)$ & \\
\hline Marital Status & & & 0.009 \\
\hline Single & $76(31.9)$ & $9(18.8)$ & \\
\hline Married & $160(67.2)$ & $36(75.0)$ & \\
\hline Divorced & $2(0.8)$ & $3(6.2)$ & \\
\hline Education Level & & & 0.032 \\
\hline Illiterate & $19(8.0)$ & $9(18.8)$ & \\
\hline High school & $146(61.3)$ & $26(54.2)$ & \\
\hline Diploma & $60(25.2)$ & $11(22.9)$ & \\
\hline Post diploma & $2(0.8)$ & $2(4.2)$ & \\
\hline Bachelor & $11(4.6)$ & $0(0.0)$ & \\
\hline Economic Status & & & 0.437 \\
\hline Poor & $36(12.6)$ & $7(2.4)$ & \\
\hline Average & $196(68.5)$ & $38(13.3)$ & \\
\hline Good & $5(1.7)$ & $3(1.0)$ & \\
\hline Excellent & $1(0.3)$ & $0(0.0)$ & \\
\hline Age group, y & & & 0.000 \\
\hline $15-35$ & $157(66)$ & $25(52.1)$ & \\
\hline $36-56$ & $72(30.3)$ & $12(25)$ & \\
\hline$>56$ & $9(3.8)$ & $11(22.9)$ & \\
\hline \multicolumn{4}{|l|}{ Occupation } \\
\hline Worker & $142(59.7)$ & $28(58.3)$ & 0.093 \\
\hline Teacher & $12(5.0)$ & $0(0.0)$ & \\
\hline Housekeeper & $40(16.8)$ & $15(31.2)$ & \\
\hline Unemployed & $11(4.6)$ & $1(2.1)$ & \\
\hline Student & $26(10.9)$ & $2(4.2)$ & \\
\hline Staff & $7(2.9)$ & $2(4.2)$ & \\
\hline
\end{tabular}

Table 2. Scores of Brief Symptoms Inventory Scales and Global Severity Index in Patients With Mild Traumatic Brain Injury ${ }^{\text {a }}$

\begin{tabular}{|c|c|c|c|c|}
\hline \multirow[t]{2}{*}{ BSI Dimensions } & \multicolumn{3}{|c|}{ Scores, mean \pm SD } & \multirow[t]{2}{*}{ P Value } \\
\hline & Females & Males & Total & \\
\hline Anxiety & $1.60 \pm 0.85$ & $1.35 \pm 0.85$ & $1.40 \pm 0.85$ & 0.04 \\
\hline Obsession & $1.58 \pm 0.85$ & $1.53 \pm 0.84$ & $1.54 \pm 0.84$ & 0.70 \\
\hline Phobia & $1.42 \pm 0.78$ & $1.26 \pm 0.78$ & $1.29 \pm 0.78$ & 0.14 \\
\hline Anger/hostility & $1.14 \pm 0.78$ & $1.31 \pm 0.82$ & $1.28 \pm 0.81$ & 0.14 \\
\hline Paranoid & $1.51 \pm 0.80$ & $1.41 \pm 0.84$ & $1.43 \pm 0.83$ & 0.41 \\
\hline $\begin{array}{l}\text { Interpersonal } \\
\text { Sensitivity }\end{array}$ & $1.33 \pm 0.68$ & $1.39 \pm 0.73$ & $1.38 \pm 0.72$ & 0.58 \\
\hline Psychotics & $1.33 \pm 0.62$ & $1.35 \pm 0.71$ & $1.34 \pm 0.69$ & 0.89 \\
\hline Depression & $1.52 \pm 0.73$ & $1.36 \pm 0.70$ & $1.39 \pm 0.71$ & 0.13 \\
\hline Somatization & $1.42 \pm 0.77$ & $1.26 \pm 0.78$ & $1.29 \pm 0.78$ & 0.16 \\
\hline GSI & $1.45 \pm 0.54$ & $1.37 \pm 0.59$ & $1.39 \pm 0.58$ & 0.36 \\
\hline
\end{tabular}

Table 3. Results of Logistic Regression Models of the Predictor Variables for Developing Psychologic Disorders in Patients With Traumatic Brain Injury

\begin{tabular}{lcccccc}
\hline \multirow{2}{*}{ Models } & \multicolumn{5}{c}{$\begin{array}{l}\text { Unstandardized Standardized P Value } \\
\text { Coefficients }\end{array}$} & \multicolumn{3}{c}{ Coefficients } \\
\cline { 2 - 5 } & B & Std. Error & Beta & $t$ & \\
\hline $\begin{array}{l}\text { History of mental } \\
\text { disorder }\end{array}$ & 0.411 & 0.105 & 0.094 & 3.92 & 0.000 \\
$\begin{array}{l}\text { GCS at the time of } \\
\text { admission }\end{array}$ & 0.08 & 0.006 & 0.792 & 13.339 & 0.000 \\
Job (staff) & -0.347 & 0.126 & -0.062 & -2.746 & 0.006 \\
Age & 0.005 & 0.003 & 0.125 & 2.069 & 0.039 \\
\hline
\end{tabular}

Our findings are also inconsistent with those of another research that found depression in $19 \%$ of patients with TBI (26). The difference may be typically due to differences in the study population and design, or to the use of different instruments and procedures in different studies.

In our study, the mean score of depression in females compared to males was similar to those found by Kringlen et al. (27), who reported females are expected to experience depression more often than males do; however, it was inconsistent with findings of Jorge et al. with respect to the association between female gender and depression (28). Our results showed that women experience symptoms and complications of mental disorders more frequently than men do.

There was a significant association between domains of mental health and age. Logistic regression model showed that the symptoms of mental disorder were highest among those over 40 years of age, which was inconsistent with the results presented by Yeates et al. (29), Wade et al. (30), and Kontos et al. (31). It has been shown that the mental disorder symptoms in adolescences and youth was more than other age groups and by the increasing age, the prevalence of these disorders is reduced $(32,33)$. The high prevalence of these dysfunctions with increased age is due to lack of support and respect of family members and society from them.

In addition, the results of the study showed that there was no significant association between symptoms of mental disorder and economic status of family, which was inconsistent with the findings of Fujii et al. (34), that showed high rate of symptoms of psychologic disorders in the families with low socio-economic status are due to various factors as low income and economic problems. It seems that low income and financial poverty have important role in mental health of people (35). The psychiatric prevalence studies showed high ratios of symptoms of mental disorder in the communities with low socio-economic status (36). Poverty and economic pressures, such as low wage and not having access to housing, increased the susceptibility to mental disorders as anxiety and depression. 
The results of our study showed that the symptoms of mental disorder in people with third of guidance school education and Diploma degree were significantly more frequent than in people with high education, which and supported the findings of other investigations (37). Stressor of unemployment and limited social relationship can be the cause of the high prevalence of mental disorder. There was a significant association between history of mental disorder and symptoms of mental disorder. Finding of our study showed that preexisting factors, such as history of psychiatric illness in patients with mild TBI are important in the persistence of psychologic problems, which is consistent with the findings of Ponsford et al. (38). The prevalence of mental disorder in staff was lower than in other people. Moreover, results of this study showed that the symptoms of psychologic disorders were higher among unemployed and retired men and homemakers than among other people, which was in line with the previous studies (39-41). Probably the lack of high income, workplace stressful factors, limitation of social relationships, and uniformity of life for women can be the reasons of high prevalence of symptoms of psychologic disorders among studied worker people than in staff.

Limitations of this study were absence of detailed information such as history of mental disorder and the reliance on self-report for determining the history of psychologic disorders. This study showed that prevalence of symptoms of mental disorders among traumatic patients was $32.2 \%$ and there was a significant association with some variables as low economic status and age. The results of the study can be applied by educational and health policymakers to prevent symptoms of psychologic disorders among patients with TBI.

\section{Acknowledgements}

We thank all patients for their participation.

\section{References}

1. Anderson V, Godfrey C, Rosenfeld JV, Catroppa C. 10 years outcome from childhood traumatic brain injury. Int J Dev Neurosci. 2012;30(3):217-24.

2. Halbauer JD, Ashford JW, Zeitzer JM, Adamson MM, Lew HL, Yesavage JA. Neuropsychiatric diagnosis and management of chronic sequelae of war-related mild to moderate traumatic brain injury. J Rehabil Res Dev. 2009;46(6):757-96.

3. Jones N, Fear NT, Rona R, Fertout M, Thandi G, Wessely S, et al. Mild traumatic brain injury (mTBI) among UK military personnel whilst deployed in Afghanistan in 2011. Brain Inj. 2014;28(7):896-9.

4. Hibbard MR, Uysal S, Kepler K, Bogdany J, Silver J. Axis I psychopathology in individuals with traumatic brain injury. The Journal of head trauma rehabilitation. 1998;13(4):24-39.

5. Krug EG, Sharma GK, Lozano R. The global burden of injuries. Am J Public Health. 2000;90(4):523-6.

6. Anderson VA, Catroppa C, Dudgeon P, Morse SA, Haritou F, Rosenfeld JV. Understanding predictors of functional recovery and outcome 30 months following early childhood head injury. Neuropsychology. 2006;20(1):42-57.

7. Farzandipour M, Ghattan H, Mazrouei L, Nejati M, Aghabagheri T. Epidemiological study of traumatic patients referred to neghavi hospital of kashan. Journal of Kermanshah University of Medical Sciences. 2007;11(1).

8. Fakharian E, Fazel MR, Tabesh H, Nabavi Z. Incidence of mild head injury, management, and expenses in Kashan, 2003-2004. Feyz J Kashan Uni Medic Sci. 2007;11(3):63-7.

9. Whelan-Goodinson R, Ponsford J, Johnston L, Grant F. Psychiatric disorders following traumatic brain injury: their nature and frequency. J Head Trauma Rehabil. 2009;24(5):324-32.

10. Vasterling JJ, Brailey K, Proctor SP, Kane R, Heeren T, Franz M. Neuropsychological outcomes of mild traumatic brain injury, post-traumatic stress disorder and depression in Iraq-deployed US Army soldiers. BrJ Psychiatry. 2012;201(3):186-92.

11. Hessen E, Nestvold K, Anderson V. Neuropsychological function 23 years after mild traumatic brain injury: a comparison of outcome after paediatric and adult head injuries. Brain Inj. 2007;21(9):963-79.

12. Rona RJ, Jones M, Fear NT, Hull L, Murphy D, Machell L, et al. Mild traumatic brain injury in UK military personnel returning from Afghanistan and Iraq: cohort and cross-sectional analyses. J Head Trauma Rehabil. 2012;27(1):33-44.

13. Norrie J, Heitger M, Leathem J, Anderson T, Jones R, Flett R. Mild traumatic brain injury and fatigue: a prospective longitudinal study. Brain Inj. 2010;24(13-14):1528-38.

14. Anderson V, Catroppa C, Morse S, Haritou F, Rosenfeld JV. Intellectual outcome from preschool traumatic brain injury: a 5-year prospective, longitudinal study. Pediatrics. 2009;124(6):e1064-71.

15. Ardelt W, Mikulski SM, Shogen K. Amino acid sequence of an anti-tumor protein from Rana pipiens oocytes and early embryos. Homology to pancreatic ribonucleases. $J$ Biol Chem. 1991;266(1):245-51.

16. Lishman WA. Physiogenesis and psychogenesis in the 'post-concussional syndrome'. Br J Psychiatry. 1988;153:460-9.

17. Deb S, Lyons I, Koutzoukis C, Ali I, McCarthy G. Rate of psychiatric illness 1 year after traumatic brain injury. Am J Psychiatry. 1999;156(3):374-8.

18. Massagli TL, Fann JR, Burington BE, Jaffe KM, Katon WJ, Thompson RS. Psychiatric illness after mild traumatic brain injury in children. Arch Phys Med Rehabil. 2004;85(9):1428-34.

19. Fann JR, Burington B, Leonetti A, Jaffe K, Katon WJ, Thompson RS. Psychiatric illness following traumatic brain injury in an adult health maintenance organization population. Arch Gen Psychiatry. 2004;61(1):53-61.

20. Weyandt LL, Dupaul GJ. ADHD in college students: Developmental findings. Dev Disabil Res Rev. 2008;14(4):311-9.

21. Royse D, Drude K. Screening drug abuse clients with the brief symptom inventory. Int J Addict. 1984;19(8):849-57.

22. Shapurian R, Hojat M. Psychometric Characteristics of a Persian Version of the Eysenck Personality Questionnaire. Psychological Reports. 1985;57(2):631-9.

23. Hessel A, Schumacher J, Geyer M, Brähler E. Symptom-Checkliste SCL-90-R. Diagnostica. 2001;47(1):27-39.

24. Bryant RA, O'Donnell ML, Creamer M, McFarlane AC, Clark CR Silove D. The psychiatric sequelae of traumatic injury. Am J Psychiatry. 2010;167(3):312-20.

25. Bombardier CH, Fann JR, Temkin NR, Esselman PC, Barber J, Dikmen SS. Rates of major depressive disorder and clinical outcomes following traumatic brain injury. JAMA. 2010;303(19):1938-45.

26. Dikmen SS, Bombardier CH, Machamer JE, Fann JR, Temkin NR Natural history of depression in traumatic brain injury. Arch Phys Med Rehabil. 2004;85(9):1457-64.

27. Kringlen E, Torgersen S, Cramer V. A Norwegian psychiatric epidemiological study. Am J Psychiatry. 2001;158(7):1091-8.

28. Jorge RE, Robinson RG, Moser D, Tateno A, Crespo-Facorro B Arndt S. Major depression following traumatic brain injury. Arch Gen Psychiatry. 200 4;61(1):42-50.

29. Yeates KO, Taylor HG, Walz NC, Stancin T, Wade SL. The family environment as a moderator of psychosocial outcomes following traumatic brain injury in young children. Neuropsychology. 2010;24(3):345-56.

30. Wade SL, Cassedy A, Walz NC, Taylor HG, Stancin T, Yeates KO. The relationship of parental warm responsiveness and negativity to emerging behavior problems following traumatic brain injury in young children. Dev Psychol. 2011;47(1):119-33. 


\section{Fakharian E et al.}

31. Kontos AP, Kotwal RS, Elbin RJ, Lutz RH, Forsten RD, Benson PJ et al. Residual effects of combat-related mild traumatic brain injury. J Neurotrauma. 2013;30(8):680-6.

32. Anderson V, Moore C. Age at injury as a predictor of outcome following pediatric head injury: A longitudinal perspective. Child Neuropsychology.1995;1(3):187-202.

33. Taylor HG, Alden J. Age-related differences in outcomes following childhood brain insults: an introduction and overview. J Int Neuropsychol Soc. 1997;3(6):555-67.

34. Fujii DE, Ahmed I. Risk factors in psychosis secondary to traumatic brain injury. J Neuropsychiatry Clin Neurosci. 2001;13(1):61-9.

35. Hoofien D, Gilboa A, Vakil E, Donovick PJ. Traumatic brain injury (TBI) 10-20 years later: a comprehensive outcome study of psychiatric symptomatology, cognitive abilities and psychosocial functioning. Brain Inj. 2001;15(3):189-209.

36. Max JE, Levin HS, Landis J, Schachar R, Saunders A, Ewing-Cobbs $\mathrm{L}$, et al. Predictors of personality change due to traumatic brain injury in children and adolescents in the first six months after injury. J Am Acad Child Adolesc Psychiatry. 2005;44(5):434-42.

37. Woodward SH, Shurick AA, Alvarez J, Kuo J, Nonyieva Y, Blechert J, et al. A psychophysiological investigation of emotion regulation in chronic severe posttraumatic stress disorder. Psychophysiology. 2014.

38. Ponsford J, Willmott C, Rothwell A, Cameron P, Ayton G, Nelms R, et al. Cognitive and behavioral outcome following mild traumatic head injury in children. J Head Trauma Rehabil.1999;14(4):36072.

39. Alexander MP, Stuss DT, Picton T, Shallice T, Gillingham S. Regional frontal injuries cause distinct impairments in cognitive control. Neurology. 2007;68(18):1515-23.

40. Geva S, Jones PS, Crinion JT, Price CJ, Baron JC, Warburton EA. The neural correlates of inner speech defined by voxel-based lesionsymptom mapping. Brain. 2011;134(Pt 10):3071-82.

41. Cisler JM, Olatunji BO, Feldner MT, Forsyth JP. Emotion Regulation and the Anxiety Disorders: An Integrative Review. J Psychopathol Behav Assess. 2010;32(1):68-82. 